\title{
積層複合円筒款の静水圧座屈に及ぼす積層構成の影響
}

\section{Effect of Lamination Constitution on Buckling of Laminated \\ Composite Cylindrical Shells under Hydrostatic Pressure}

by

\section{Hirakazu KASUYA*}

Advanced fiber-reinforced laminated composite materials have been used for structural members in various fields, because of their high specific strength and stiffness. In general, laminated composite cylindrical shells behave differently from homogeneous orthotropic cylindrical shells due to their anisotropy and unsymmetric lamination.

In the present paper, the buckling problems of carbon fiber/epoxy (CFRP) cross-ply and angle-ply laminated cylindrical shells under hydrostatic pressure are considered. That is, the effects of stacking sequence, number of layers, lamination angle, buckling modes and dimension of cylinders, on the buckling pressure are analysed by assuming the buckling patterns which satisfy the equilibrium equation based on the Donnell-type expressions.

Key words : Structural analysis, Composite materials, Laminated cylindrical shells, Buckling strength, Hydrostatic pressure, Lamination constitution

\section{1 緒言}

高比強度, 高比剛性の高性能繊維強化プラスチック 材が最近開発され, 各分野の構造に数多く用いられる ようになってきた。このような異方性材料よりなる積 層複合円筒款は, 積層配列や強化繊維の配向等によっ てはカップリング効果などの各種の積層構成効果があ り，単純な直交異方性積層理論による均質な直交異方 性円筒壳とは異なる力学的挙動を示す. そこで, この ような積層複合円筒款の各種外圧のもとでの座屈現象 を的確に把握しておく必要が生じ, 数例の解析的研究 の報告がなされている。

本論文では，海中構造物に見られるような，半径方 向および軸方向に均一な外圧力を受ける問題を取り上 げ，クロスプライおよびアングルプライ積層円筒款を 例にとって，前報と同様な手法を用いて理論解析し， 積層構成, 積層数の他に, 特に前報では取り上げな かった積層順序, 殼の形状寸法などの静水圧座屈に及 ほす影響を系統的に検討し, 最適積層構成に対する参 考資料とする.

\section{2 座 屈解 析 法}

Fig. 1 に示すような積層円筒壳（半径 $R$, 筒長 $L$, 板厚 $t$ ） が半径方向と軸方向に均一な外圧力 $p$ を受 ける場合について考え, 円筒軸方向, 円周方向, 半径
方向にそれぞれ $x, y, z$ 軸をとる. また, Fig. 2 に 示すように，積層円筒殸は各層とも均質な直交異方性 材の $N$ 層積層からなり， $k$ 番目の層は基準面から $z$ $=t_{k}-t_{k+1}$ 間に存在し, 䋊維は円筒主軸と角度 $\theta_{k}$ の 方向を向いているとする.

\section{$2 \cdot 1$ 積層円筒殼の基礎式}

一般的な積層円筒款が半径方向と軸方向に均一な外

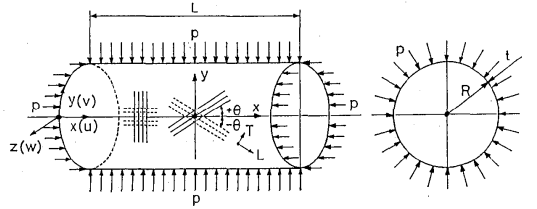

Fig. 1. Configuration and coordinates of laminated composite cylindrical shell.

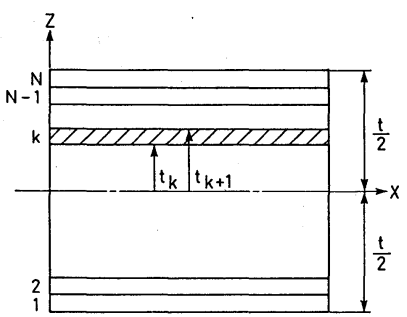

Fig. 2. Geometry of an $N$-layered laminate.

$†$ 原稿受理 平成元年 1月 9日 Received Jan. 9, 1989

* 正会員 東海大学工学部 平塚市北金目, Faculty of Engineering, Tokai University, Kitakaname, Hiratsuka 
圧力 $p$ を受けて座屈するときの付加的変位 $u, v, w$ を用いて表した Donnell 形の平衡方程式は次式とな る.

$x$ 方向;

$$
\begin{aligned}
& \mathrm{A}_{11} u,_{x x}+\mathbf{A}_{12}\left(v_{x_{x y}}+w_{x} / R\right)+\mathbf{A}_{16}\left(v_{x x}\right. \\
& \left.+u,_{x y}\right)-\mathbf{B}_{11} w_{x_{x x x}}-\mathbf{B}_{12} w_{x_{x y y}}-2 \mathbf{B}_{16} w_{x x y} \\
& +\mathbf{A}_{16} u,_{x y}+\mathbf{A}_{26}\left(v,_{y y}+w,_{y} / R\right)+\mathbf{A}_{66}\left(v,_{x y}\right. \\
& \left.+u,_{y y}\right)-\mathbf{B}_{16} w,_{x x y}-\mathbf{B}_{26} w_{y y y}-2 \mathbf{B}_{66} w_{x y y} \\
& =0
\end{aligned}
$$

$y$ 方向 ;

$$
\begin{aligned}
& \mathbf{A}_{16} u,_{x x}+\mathbf{A}_{26}\left(v,_{x y}+w_{,_{x}} / R\right)+\mathbf{A}_{66}\left(v,_{x x}\right. \\
& \left.+u,_{x y}\right)-\mathbf{B}_{16} w_{x x x}-\mathbf{B}_{26} w,_{x y y}-2 \mathbf{B}_{66} w,_{x x y} \\
& +\mathbf{A}_{12} u,_{x y}+\mathbf{A}_{22}\left(v,_{y y}+w_{y} / R\right)+\mathbf{A}_{26}\left(v,_{x y}\right. \\
& \left.+u_{y_{y y}}\right)-\mathbf{B}_{12} w_{x x y}-\mathbf{B}_{22} w,_{y y y} \\
& -2 \mathbf{B}_{26} w_{x y y}=0
\end{aligned}
$$

$z$ 方向;

$$
\begin{aligned}
& \mathrm{B}_{11} u,_{x x x}+\mathrm{B}_{12}\left(v,_{x x y}+w_{x x} / R\right)+\mathrm{B}_{16}\left(v_{x x x}\right. \\
& \left.+u,_{x x y}\right)-\mathrm{D}_{11} w_{x_{x x x x}}-\mathrm{D}_{12} w_{x_{x x y y}}-2 \mathrm{D}_{16} w_{x_{x x x y}} \\
& +2\left\{\mathrm{~B}_{16} u,_{x x y}+\mathrm{B}_{26}\left(v,_{x y y}+w_{x y} / R\right)+\mathrm{B}_{66}\left(v,_{x x y}\right.\right. \\
& \left.\left.+u,_{x y y}\right)-\mathrm{D}_{16} w_{x x x y}-\mathrm{D}_{26} w_{x y y y}-2 \mathrm{D}_{66} w_{x x y y}\right\} \\
& +\mathbf{B}_{12} u,_{x y y}+\mathbf{B}_{22}\left(v v_{y y y}+w_{y y} / R\right)+\mathbf{B}_{26}\left(v_{x y y}\right. \\
& \left.+u,_{y y y}\right)-\mathrm{D}_{12} w_{x x y y}-\mathrm{D}_{22} w_{\text {,yyy }}-2 \mathrm{D}_{26} w_{\text {,xyyy }} \\
& -\left\{\mathbf{A}_{12} u, x+\mathbf{A}_{22}\left(v,{ }_{y}+w / R\right)+\mathbf{A}_{26}\left(v,{ }_{x}+u,_{y}\right)\right. \\
& \left.-\mathrm{B}_{12} w_{{ }_{x x}}-\mathrm{B}_{22} w_{y_{y y}}-2 \mathrm{~B}_{26} w_{x_{x y}}\right\} / R \\
& +\bar{N}_{x} w_{x x}+\bar{N}_{y} w_{y_{y y}}=0
\end{aligned}
$$

ここで，添字 “,”，“,” は $x, y$ に関する偏微分 を意味し， $\mathrm{A}_{i j}, \mathrm{~B}_{i j}, \mathrm{D}_{i j}(i, j=1,2,6)$ は，それぞ れ伸張剛性マトリックス，カップリング剛性マトリッ クス，曲げ剛性マトリックスである。．また， $\bar{p}$ を座屈 時静水圧とし, $\bar{N}_{x}$ は軸方向膜力 $(=\bar{p} R / 2), \bar{N}_{y}$ は円 周方向膜力 $(=\bar{p} R)$ である.

\section{$2 \cdot 2$ 静水圧座屈值の解析}

$2 \cdot 2 \cdot 1$ クロスプライ積層円筒殼 クロスプライ 積層円筒凯は，軸方向 $\left(0^{\circ}\right)$ と円周方向 $\left(90^{\circ}\right)$ の 2 層を交互に積層したもので，単純支持の境界条件（ $S$ -2) $\left[x=0, L\right.$ で $\left.w=M_{x}=N_{x}=v=0\right]$ と平衡方程式 (1) を満足する座屈波形

$$
\begin{aligned}
& u=u_{m n} \cos (m \pi x / L) \sin (n y / R) \\
& v=v_{m n} \sin (m \pi x / L) \cos (n y / R) \\
& w=w_{m n} \sin (m \pi x / L) \sin (n y / R)
\end{aligned}
$$

を式 (1)に代入すれば各項は同じ関数形となり，変位 係数に関する連立同次方程式を解けば座屈值が後述の 式(4)から求められる.

$2 \cdot 2 \cdot 2$ アングルプライ積層円筒壳 アングルプ ライ積層円筒凯は, 円筒主軸に対して $(+\theta),(-\theta)(\theta$ $\left.=0^{\circ} \sim 90^{\circ}\right)$ の 2 層を交互に積層したもので, 多くの カップリング項があり, 境界条件と平衡方程式の両者 を厳密に満足する解析解を得ることは難しい，そこで，
ある程度の筒長を有する場合を考え，平衡方程式のみ を完全に満足する周期解を用いて近似的に検討する. すなわち, 非対称変形座屈様式として

$$
\begin{aligned}
& u=u_{m n} \sin \{(m \pi x / L)+(n y / R)\} \\
& v=v_{m n} \sin \{(m \pi x / L)+(n y / R)\} \\
& w=w_{m n} \cos \{(m \pi x / L)+(n y / R)\}
\end{aligned}
$$

を考え，式 (1)に代入すると，式(1)の各項は同じ関数 形となり, 変位係数に関する連立同次方程式となる.

$2 \cdot 2 \cdot 3$ 座屈値の解析式 クロスプライ積層円筒 款, アングルプライ積層円筒殼の場合ともに座屈值は 次の係数行列式から固有值として解析式で得られる.

$$
\left|\begin{array}{ccc}
\mathrm{T}_{11} & \mathrm{~T}_{12} & \mathrm{~T}_{13} \\
\mathrm{~T}_{12} & \mathrm{~T}_{22} & \mathrm{~T}_{23} \\
\mathrm{~T}_{13} & \mathrm{~T}_{23} & \mathrm{~T}_{33}
\end{array}\right|=0
$$

ここで

$$
\begin{aligned}
\mathrm{T}_{11}= & \mathrm{A}_{11}(m \pi / L)^{2}+2 \mathrm{~A}_{16}(m \pi / L)(n / R) \\
& +\mathrm{A}_{66}(n / R)^{2} \\
\mathrm{~T}_{12}= & \mathrm{A}_{16}(m \pi / L)^{2}+\left(\mathrm{A}_{12}+\mathrm{A}_{66}\right)(m \pi / L)(n / R) \\
& +\mathrm{A}_{26}(n / R)^{2} \\
\mathrm{~T}_{22}= & \mathrm{A}_{66}(m \pi / L)^{2}+2 \mathrm{~A}_{26}(m \pi / L)(n / R) \\
& +\mathrm{A}_{22}(n / R)^{2} \\
\mathrm{~T}_{13}= & -\left\{\mathrm{A}_{12}(m \pi / L) / R+\mathrm{B}_{11}(m \pi / L)^{3}\right. \\
& +3 \mathrm{~B}_{16}(m \pi / L)^{2}(n / R)+\left(\mathrm{B}_{12}\right. \\
& \left.+2 \mathrm{~B}_{66}\right)(m \pi / L)(n / R)^{2} \\
& \left.+\mathrm{B}_{26}(n / R)^{3}+\mathrm{A}_{26}(n / R) / R\right\} \\
\mathrm{T}_{23}= & -\left\{\mathrm{A}_{26}(m \pi / L) / R+\mathrm{B}_{16}(m \pi / L)^{3}\right. \\
& +\left(\mathrm{B}_{12}+2 \mathrm{~B}_{66}\right)(m \pi / L)^{2}(n / R) \\
& +3 \mathrm{~B}_{26}(m \pi / L)(n / R)^{2}+\mathrm{B}_{22}(n / R)^{3} \\
& +\mathrm{A}_{22}(n / R) / R \\
\mathrm{~T}_{33}= & \mathrm{A}_{22} / R^{2}+2 \mathrm{~B}_{12}(m \pi / L)^{2} / R \\
& +4 \mathrm{~B}_{26}(m \pi / L)(n / R) / R+2 \mathrm{~B}_{22}(n / R)^{2} / R \\
& +\mathrm{D}_{11}(m \pi / L)^{4}+4 \mathrm{D}_{16}(m \pi / L)^{3}(n / R) \\
& +2\left(\mathrm{D}_{12}+2 \mathrm{D}_{66}\right)(m \pi / L)^{2}(n / R)^{2} \\
& +4 \mathrm{D}_{26}(m \pi / L)(n / R)^{3} \\
& \left.+\mathrm{D}_{22}(n / R)^{4}+\bar{N} y(n / R)^{2}+(m \pi / L)^{2} / 2\right\}
\end{aligned}
$$

静水圧座屈值は, $K_{0}=\bar{p} R / E_{T} t$ のように無次元値 で表わすと，款の材料定数の他に形状因子 $R / t, \mathrm{Z}$ $=L^{2} / R t$ の関数であり, 各種の波数 $m, n$ の整数值 に対するその最小値に相当する.

\section{3 数值計算例と解析結果の検討}

数值計算例としては, カーボン繊維強化プラスチッ ク（CFRP）材を考える. その基本の弾性材料定数 は平均化近似解析による式により計算され，実験で確 かめられた次の值である.

$$
\begin{aligned}
& E_{L}=137 \mathrm{GPa}, E_{T}=8.17 \mathrm{GPa} . \\
& G_{L T}=4.75 \mathrm{GPa}, \nu_{L}=0.316, \nu_{T}=0.0189
\end{aligned}
$$

本計算例では, 板厚 $t$ のもとで, 各構成層は等厚 
とし，したがって積層数 $N$ は対称積層の場合は奇数, 逆対称積層の場合は偶数として考える.

\section{$3 \cdot 1$ クロスプライ積層円筒殼の検討}

クロスプライ積層円筒凯の数值計算結果を, 対称積 層で最内層積層角を $0^{\circ}$ とした場合を Fig. 3 に，最内 層積層角を $90^{\circ}$ とした場合を Fig. 4 に，逆対称積層の 場合を Fig. 5 に示す.

（1）形状パラメータ Z,$R / t$ の影響 座屈係数 $\mathrm{K}_{0}$ と形状パラメータ Z との関係は, 対称積層, 逆対称 積層の場合ともに, いずれの $R / t$ に対しても Z の増 加にともない $\mathrm{K}_{0}$ 值は低下している．通常の円筒殸で Z>100 とすれば，Fig. 3 ～Fig. 5 でわかるように $\mathrm{K}_{0}$ 值の低下は両対数表示で直線的なので, $\mathrm{K}_{0}=\alpha / \mathrm{Z}^{\beta}$ の 形で表わされる。ここで指数 $\beta$ は $R / t$ にほぼ無関倸 に一定值をとるが，係数 $\alpha$ は積層構成，積層数，積 層順序などによって異なる值を示す。

座屈係数に及ぼす $R / t$ の影響は, 軸圧縮座屈の場

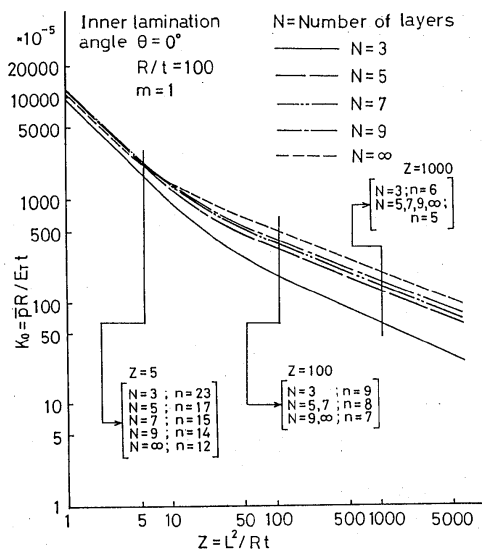

(a) $R / t=100$

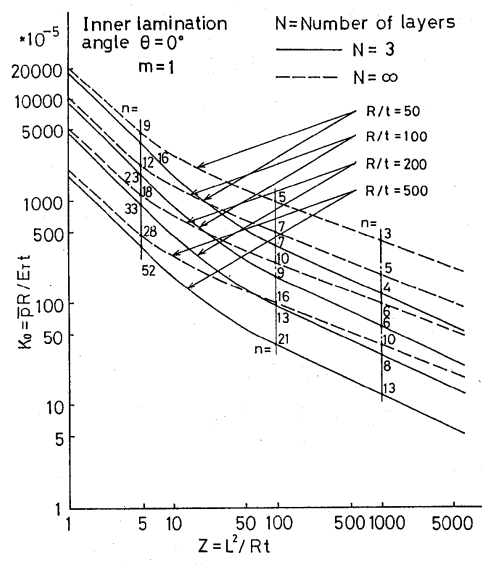

(b) $R / t=50 \sim 500$.

Fig. 3. Variation of buckling coefficients of symmetric cross-ply laminated cylindrical shells with shape parameter $Z$. (Inner lamination angle $\theta=0^{\circ}$ ).
合には現れないが，静水圧座屈の場合には，対称積層， 逆対称積層の場合ともに, $R / t$ が大きくなるととも に座屈係数は低下寸る．これは等方性材料の場合と同 じである。

（2）積層数 $N$ の影響 対称積層の場合には，カッ プリング効果はないが，クロスプライ比の変化による 各種剛性值の変化が $\mathrm{K}_{0}$ 值に及ぼす影響が大きく，最 内層積層角が $0 \circ$ の場合には，積層数の減少による $\mathrm{K}_{0}$ 值の低下が顕著に現れ，Zの増加とともにその差は 大きくなっている. また, 最内層積層角が $90^{\circ}$ の場合 には，積層数の減少にともない $\mathrm{K}_{0}$ 值は増加する.こ のように対称積層では, 最内層積層角を $0^{\circ}$ とした場 合と $90^{\circ}$ とした場合とでは，積層数の多少が $\mathrm{K}_{0}$ 値に 及ぼす影響は逆で両者の差が明確になり，積層順序が 座屈値に及ぼす影響は顕著になってくる。これは後述 のアングルプライ積層円筒殼のところで示してあるよ

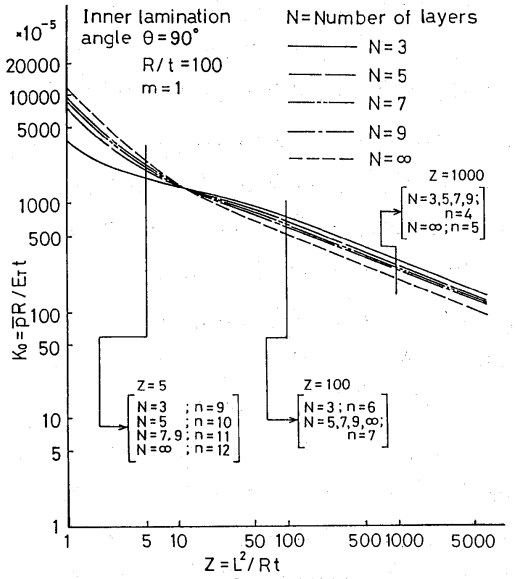

(a) $R / t=100$

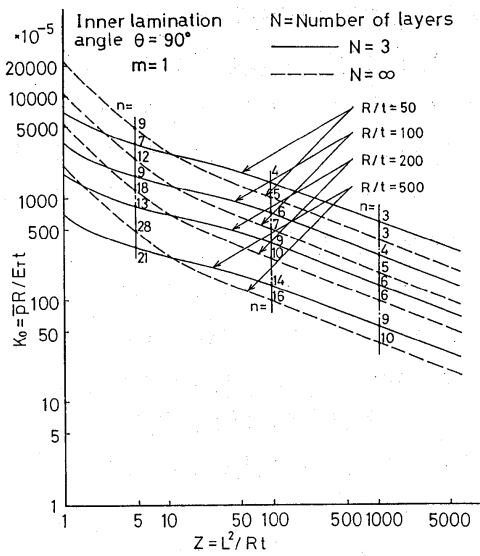

(b) $R / t=50 \sim 500$.

Fig. 4. Variation of buckling coefficients of symmetric cross-ply laminated cylindrical shells with shape parameter $Z$. (Inner lamination angle $\theta=90^{\circ}$ ). 
うに，積層角が $0^{\circ} よ り も 90^{\circ}$ のほうが高い座屈值を 与えるからである.

逆対称積層の場合には, クロスプライ比は一定值 1.0 となるが，中央面と中立面とが異なるために生ず る伸張一曲げカップリング効果が現れ, $\mathrm{K}_{0}$ 值は積層数 が少ないと低下し，特に2 層の場合に著しい低下を示 した。

(3) 座屈波形の影響 最小座屈值を与える座屈波数 のうち, 軸方向半波数 $m$ は対称積層, 逆対称積層に 関係なくすべての積層数 $N$, 形状パラメータ $R / t$, $\mathrm{Z}$ に対して 1 であり，軸方向に半波形で座屈する. しかし，円周方向波数 $n$ は図中に示してあるように， $\mathrm{Z}$ の増加および $R / t$ の減少にともない減少する.ま た $N$ の変化による $n$ は, 最内層積層角が $0^{\circ}$ の対称積 層および逆対称積層の場合には $N$ の増加にともない, 最内層積層角が $90^{\circ}$ の対称積層の場合には $N$ の減少 にともない減少する。

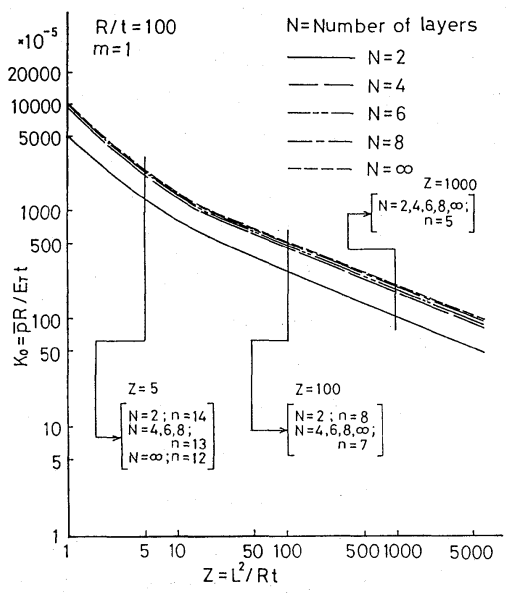

(a) $R / t=100$.

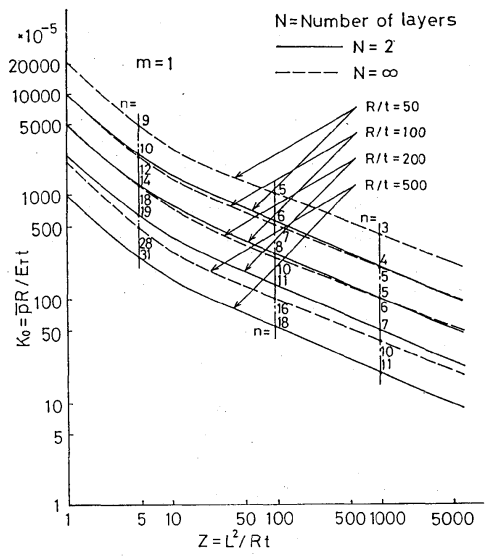

(b) $R / t=50 \sim 500$.

Fig. 5. Variation of buckling coefficients of antisymmetric cross-ply laminated cylindrical shells with shape parameter $Z$.
（4）積層順序の影響 対称積層では，最内層積層角 を $0^{\circ}$ とした場合と $90^{\circ}$ とした場合とでは，前述した ように積層順序が座屈値に及ぼす影響は大きく現れる。 しかし逆対称積層では, 伸張剛性 $\mathrm{A}_{11}$ と $\mathrm{A}_{22}$ および曲 げ剛性 $\mathrm{D}_{11}$ と $\mathrm{D}_{22}$ の值が同一になるため, 積層順序が 座屈値に与える影響はなくなる.

\section{$3 \cdot 2$ アングルプライ積層円筒壳の検討}

アングルプライ積層円筒殼の数值計算結果を，対称 積層の場合を Fig. 6 に，逆対称積層の場合を Fig. 7 に 示す．座屈值に及ぼす形状パラメータ Z の影響は, クロスプライ積層円筒款の場合と同様に表わされるの で，一例として $\mathrm{Z}=900$ の場合について示している.

（1）積層角 $\theta$ の影響 座屈係数 $\mathrm{K}_{0}$ と積層角 $\theta$ との 関係は, 対称積層, 逆対称積層の場合ともに, いずれ の積層数, 形状パラメータに対しても， $\theta$ の増加にと

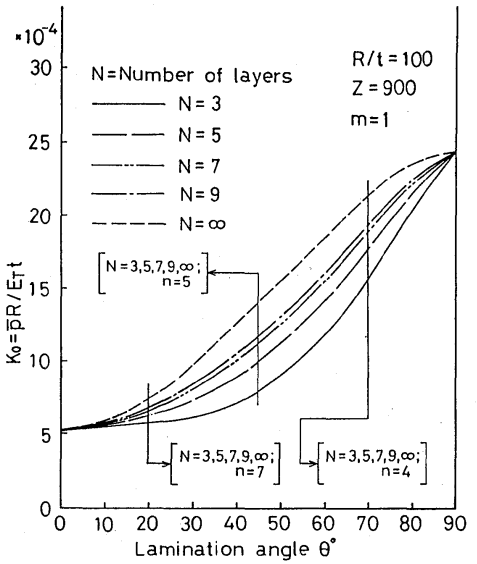

(a) $R / t=100$.

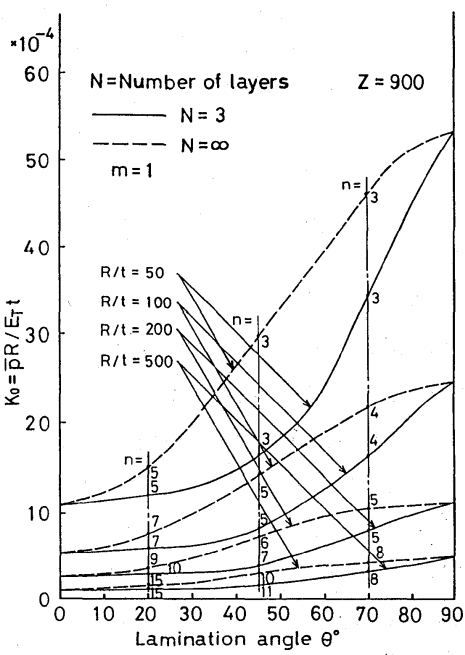

(b) $R / t=50 \sim 500$.

Fig. 6. Variation of buckling coefficients of symmetric angle-ply laminated cylindrical shells with lamination angle $\theta$. 


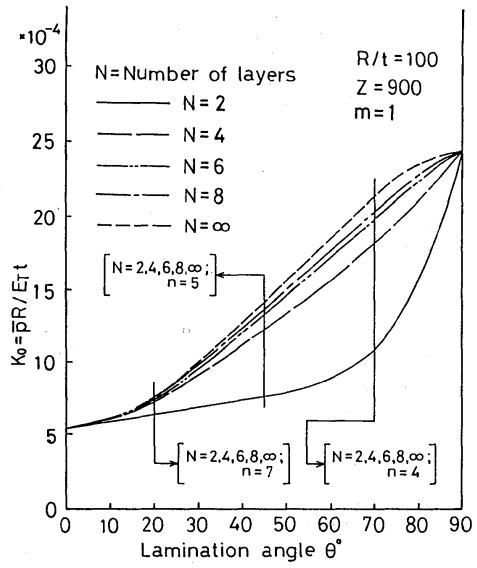

(a) $R / t=100$

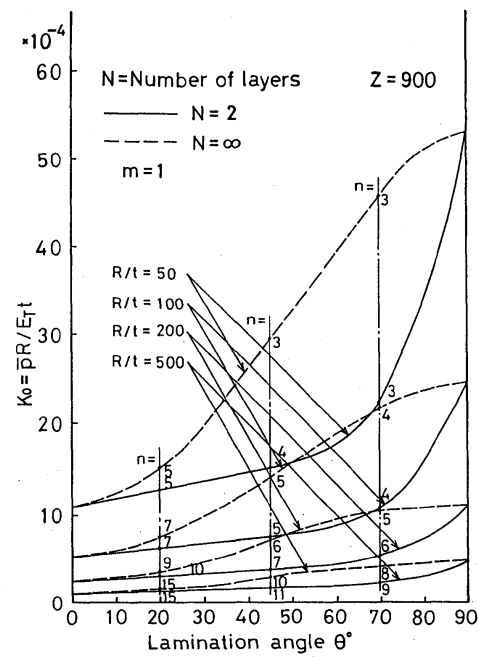

(b) $R / t=50 \sim 500$

Fig. 7. Variation of buckling coefficients of antisymmetric angle-ply laminated cylindrical shells with lamination angle $\theta$.

もなって増加し， $\theta=0^{\circ}$ のときに最小值を, $\theta=90^{\circ}$ の ときに最大值を示す。これは円周方向に波形をもつ座 屈波形を呈するからである.

(2) 形状パラメータ $\boldsymbol{R} / \boldsymbol{t}$. 影響 座屈係数に及ほ す $R / t$ の影響は, 軸圧縮座屈の場合には, クロスプ ライ積層円筒殼の場合と同様に現れないが, 静水圧座 屈の場合には，対称積層，逆対称積層の場合ともに， ある $\mathrm{Z}$ 值のもとで, 形状パラメータ $R / t$ が大きくな るとともに $\mathrm{K}_{0}$ 值は低下する.

（3）積層数 $N$ の影響 積層数 $N$ の変化による $\mathrm{K}_{0}$ 值の低下は, 積層角 $\theta=0^{\circ}, 90^{\circ}$ の場合にはないが, その中間の積層角 $0^{\circ}<\theta<90^{\circ}$ の場合には，対称積層 では伸張一せん断カップリング効果により, 逆対称積 層では伸張-ねじり（せん断-曲げ）カップリング効果 により，ともに積層数が少なくなると顕著に現れる.
特に 2 層の逆対称積層の場合には著しい低下を示し, 他の積層構成の場合とは異なる挙動を示した.

（4）座屈波形の影響 最小座屈值を与える座屈波数 のうち, 軸方向半波数 $m$ は, 積層角, 積層数, 形状 パラメー夕に関係なく 1 である. また円周方向波数 $n$ は, 積層角, 形状パラメータの変化により増減するが, 積層数の変化による差はあまり現れない.

以上のことを, 前報の半径方向均一外圧の場合と比 較検討すると, クロスプライおよびアングルプライ積 層円筒壳の場合ともに, 静水圧座屈のほうが極くわず か低い座屈值を示し，危険側にくるので，その点注意 しなければならない. しかし， $\mathrm{Z}$ 打よび $R / t$ が大き くなり，いわゆる円筒殸らしくなるにつれて両者の相 異はきわめて小さくなり，同一と見なしてもさしつか えない.

\section{4 結言}

本論文は, 半径方向均一外圧のもとで解かれた積層 複合円筒殻の座屈を, 軸方向外圧も合せて受けるいわ ゆる静水圧の場合に拡張したものである. Donnell 形 の方程式により座屈値を解析し，代表的な CFRPに ついて, 形状パラメータ $R / t, \mathrm{Z}\left(=L^{2} / R t\right)$ に対して 無次元值で表示した.

特に，座屈特性に及ほす積層構成効果の影響を調へ， 積層構成, 積層順序, 積層数, 積層角, 形状パラメー 夕などの変化が積層構成効果に大きく影響することを 示した.

本論文では, 面内変形と面外変形とが連成する問題 の座屈值を求めたが, 積層構成効果を考虑した積層構 成の最適化を行うことが今後の課題である.

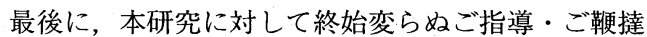
をいただいた日本大学生産工学部植村益次教授に厚く 感謝いたします。

（昭和 63 年 12 月 9 日 第 32 回材料研究連合講演会にて講演）

\section{参 考 文 献}

1) R. M. Jones and H. S. Morgan, AIAA J., 13, 664 (1975).

2 ) 粕谷平和, 植村益次, 材料, 34, 262 (1985).

3 ）大矢弘史，日本機械学会論文集，A-53，288（1987).

4) R. M. Jones, "Mechanics of Composite Materials", Chap. 4 (1975) Mc Graw-Hill, New York.

5 ) 植村益次, 山田直樹, 材料, 24, 156 (1975).

6 ) 粕谷平和, 植村益次, 日本航空宇宙学会誌, $\mathbf{3 0}, 664$ (1982).

7 ) 粕谷平和, 植村益次, 日本機械学会論文集, A-51，393 (1985). 